\title{
A qualitative grounded theory study of the conceptions of clinical practice in osteopathy. A continuum from technical rationality to professional artistry
}

\author{
Oliver P. Thomson, Nicola J. Petty, Ann P. Moore
}

\begin{abstract}
a b s t r a c t
How practitioners conceive clinical practice influences many aspects of their clinical work including how they view knowledge, clinical decision-making, and their actions. Osteopaths have relied upon the philosophical and theoretical foundations upon which the profession was built to guide clinical practice. However, it is currently unknown how osteopaths conceive clinical practice, and how these conceptions develop and influence their clinical work. This paper reports the conceptions of practice of experienced osteopaths in the UK.

A constructivist grounded theory approach was taken in this study. The constant comparative method of analysis was used to code and analyse data. Purposive sampling was employed to initially select participants. Subsequent theoretical sampling, informed by data analysis, allowed specific participants to be sampled. Data collection methods involved semi-structured interviews and non-participant observation of practitioners during a patient appointment, which was video-recorded and followed by a videoprompted reflective interview.

Participants' conception of practice lay on a continuum, from technical rationality to professional artistry and the development of which was influenced by their educational experience, view of health and disease, epistemology of practice knowledge, theoryepractice relationship and their perceived therapeutic role.

The findings from this study provide the first theoretical insight of osteopaths' conceptions of clinical practice and the factors which influence such conceptions.
\end{abstract}

Osteopathy; Professional knowledge; Clinical reasoning; Professional artistry

\section{Introduction}

How an individual practitioner views the nature of their practice and the different aspects of their clinical work such as knowledge, skills, activities, and decision-making has been referred to as their 'conception of practice' (Fish and Coles, 1998). Conception of practice is closely associated with practitioners' views on the nature of knowledge associated with their practice; and has been explicated by various authors (Schön, 1987; Fish, 1998; Fish and Coles, 1998) in relation to technical rationality and professional artistry. These two conceptions of practice were used as the theoretical framework in this study, and their major characteristics are shown in Table 1.
Professional clinical practice requires practitioners to be aware of and reflect upon their personal conception of practice and recognise the nature of knowledge used in practice (Schön, 1987). Research that generates knowledge of how practitioners conceive the nature of practice helps to provide an understanding of what drives their actions and decision-making when they are working clinically with patients. Such research also facilitates an understanding of how practitioners learn from practice and develop as practitioners (Richardson et al., 2004). For example, the literature suggests that the views and assumptions that manual therapists' hold about different aspects of their clinical work, such as the body (Thornquist, 1991, 2006; Nicholls and Gibson, 2010), movement (Edwards et al., 2006) and their professional role (Thornquist, 2006; Evans, 2007; Lindquist et al., 2010), influences the way in which they practice. Recent research in musculoskeletal physiotherapy indicates that how practitioners conceive clinical practice and view practice knowledge influences the way in which they 
Table 1

Two views of professional practice (Schön, 1987; Fish and Coles, 1998)

\begin{tabular}{|c|c|}
\hline $\begin{array}{l}\text { Technical rational } \\
\text { conception of practice }\end{array}$ & $\begin{array}{l}\text { Professional artistry conception } \\
\text { of practice }\end{array}$ \\
\hline Follows rules, laws and routines & $\begin{array}{l}\text { Starts where rules fade, sees patterns } \\
\text { and frameworks }\end{array}$ \\
\hline Analyses & Interprets \\
\hline Practice is efficient & Practice is creative \\
\hline $\begin{array}{l}\text { Sees knowledge as graspable } \\
\text { and permanent }\end{array}$ & $\begin{array}{l}\text { Knowledge is temporary, dynamic } \\
\text { and problematic }\end{array}$ \\
\hline $\begin{array}{l}\text { Technical expertise } \\
\text { and skill is central }\end{array}$ & Professional judgement counts \\
\hline Emphasises the known & Embraces uncertainty \\
\hline $\begin{array}{l}\text { Sees professional activities } \\
\text { as masterable }\end{array}$ & $\begin{array}{l}\text { See mystery at the heart } \\
\text { of professional practice }\end{array}$ \\
\hline $\begin{array}{l}\text { Problems are simple } \\
\quad \text { and straightforward }\end{array}$ & Problems are complex and ambiguous \\
\hline Theory is applied to practice & Theory emerges from practice \\
\hline
\end{tabular}

learn and develop clinical expertise (Petty, 2009; Petty et al. 2011a,b).

Although the nature of knowledge and its relation to professional practice has featured in the literature for over century (Ryle, 1949; Polanyi, 1967; Schön, 1983; Eraut, 1994; Higgs and Titchen, 2001a) and far beyond (Aristotle, 1975), it is only relatively recently that researchers have begun to explore these aspects of practice in relation to manual therapy. In the last twenty years, healthcare professions have begun to research how their practitioners conceive clinical practice and the nature of their clinical reasoning, including musculoskeletal physiotherapy (Jensen et al., 2000; Edwards et al., 2004; Petty et al., 2011a, b), and occupational therapy (Fleming, 1991a, b; Paterson et al., 2005, 2006).

The manual therapy professions are continuing to grow and becoming increasingly competitive in the provision of musculoskeletal care (Foster et al., 2012; NHS, 2012). Osteopathy in the UK is a growing manual therapy profession and practitioner numbers currently exceed 4500 (GOsC, 2012). As part of this development, osteopathy has been included in national guidelines for the management of non-specific low back pain (NICE, 2009). As a profession, osteopathy is required to be critically reflective, evaluative, and constantly questioning in order to develop its knowledge-base and to enhance patient care (Richardson et al., 2004). However, how osteopaths conceive clinical practice and the factors which influence the development of such conceptions is currently unknown. This paper explores the conceptions of practice of experienced osteopaths using existing theory present in the literature as a theoretical framework (Fish and Coles, 1998). The findings from this study form part of a broader theory of osteopaths' clinical decision-making and therapeutic approaches reported elsewhere (Thomson, 2013; Thomson et al., 2013).

\section{Methodology}

\subsection{Study design}

This study took a constructivist grounded theory approach (Charmaz, 2006) situated in the interpretive research paradigm. In line with iterative process of grounded theory data collection and analysis occurred concurrently (Charmaz, 2006). The constant comparative method of analysis was used to analyse data. Purposive sampling was employed to initially select participants. Subsequent theoretical sampling, guided by data analysis, allowed specific participants to be sampled. Data collection methods involved semistructured interviews and non-participant observation of practitioners during a patient appointment, which were video-recorded and followed by a video-prompted reflective interview (Haw and
Hadfield, 2011). All interviews were audio-recorded and transcribed verbatim. Table 2 provides examples of questions that were used during interviews. The methods used in this study have been presented in detail elsewhere (Thomson, 2013; Thomson et al., 2013).

\subsection{Participants}

Twelve UK registered osteopaths participated in this study. Biographical information is provided in Table 3. Approval was granted by the Faculty of Health and Social Science Research Ethics and Governance Committee at the University of Brighton and the Ethics Committee of the British College of Osteopathic Medicine.

\section{Findings}

\subsection{Conception of practice}

Participants' conception of practice lay on a continuum, from technical rationality to professional artistry (Fish and Coles, 1998). Some participants' conceptions lay at the extreme ends of the continuum whereas others fell in between the two extremes. Participants that conceived practice as technical rationality tended to see problems through a lens which viewed the patient's problems as relatively simple biomechanical, anatomical and physiological deviations from normal, and could be known by technical examination procedures:

If somebody's got left-sided low back pain and their pelvis tilts down to the right then the structures will be more compressed on that side. (P8)

I know that the medial collateral ligament strain is being caused by the rotation in the pelvis. (P1)

Their focus on obtaining propositional knowledge of patients' bodies meant they tended not to consider the psychological and social aspects of the patient. They considered that their technical hands-on skills were central to their practice and was the essence of their expertise.

A conception of practice of technical rationality resulted in participants analysing possible causeeeffect relationships behind patients' problems, and this was instrumental in their clinical decision-making:

If I can find the exact action that produces pain then I can have an idea of what kind of tissue is involved and start to think about treatment. (P5)

And they tended to lead the clinical decision-making based on their analysis of patients' bodies:

I will determine what treatment I think the patient needs. (P2)

Table 2

Interview questions that relate to participants conceptions of clinical practice.

What were you thinking when you were carrying out that action (examination or treatment procedure)?

Could you comment on the information gathered from that action (patient discussion or treatment, examination procedure)

What are your overall thoughts about the information you have obtained from this part of the examination?

How do you see the patient's role in your relationship? Why? Are there any exceptions?

What does it mean to 'have a partnership' with a patient?

How do you perceive your role with patients? Why? Are there any exceptions?

What do you mean by (observe, palpate, talking etc). Why is this important/how does that help you?

Can you think of any times when you have had to change your treatment approach? 
Table 3

Biographical information of study participants.

\begin{tabular}{ll}
\hline Mean age & 43.5 (Range 30e56) \\
\hline $\begin{array}{l}\text { Mean years } \\
\text { in clinical practice }\end{array}$ & 15 (Range 6e25) \\
Gender & 10 males \\
& 2 females \\
Work setting & All worked in private clinical practice \\
& 10 held additional roles as clinical tutors \\
& or lecturers at an OEI \\
Education & All had undergraduate qualifications \\
& in osteopathy (BSc, DO) \\
& 4 held additional postgraduate degrees \\
& (MSc degrees in Pain, Musculoskeletal Medicine, \\
& Sports Rehabilitation and Osteopathy) \\
\hline
\end{tabular}

OEI e Osteopathic Educational Institution; BSc e Bachelor of Science; DO e Diploma in osteopathy; MSc e Master of Science.

However, other participants conceived practice and professional artistry. They recognised the ambiguity and complexity of practice and they emphasised creativity and flexibility to construct an understanding of the individual patient and their problem:

I like to see the other factors that would be influencing the way that they experience their problem.it gives you a rounder picture of the person. (P6)

Participants with a professional artistic conception of practice appreciated sources and forms of knowledge other than propositional knowledge (biomechanical, anatomical knowledge etc). These participants blended together a range of knowledge types to guide their clinical action:

I put all of the information that I've got from the examination with patient expectation the relationship that I have got with them and then I draw on all of it to point us in the right direction. (P10)

A strong feature of participants with a conception of practice akin to professional artistry was their therapeutic use of self (Rowan and Jacobs, 2002), which enabled them to relate to the patient as a person and develop an understanding of them and their problem:

This notion of getting to know the person underneath the patient mantle is really important for meeit is absolutely vital. (P7)

In contrast, participants that conceived practice as technical rationality tended to use their physical body therapeutically, such as their hands to move and assess the patients' body:

the sense of touch and the sense of restriction, palpation helps you to identify tissue dysfunction or restrictions. (P5)

4. Factors influencing and associated with conceptions of practice

Five factors were identified which appeared to influence and be associated with participants' conception of practice. These were;

- educational experience

- view of health and disease

- epistemology of practice knowledge

- theoryepractice relationship

- practitioners' perceived therapeutic role.

These are discussed in turn and are summarised in Fig. 1.

\subsection{Educational experience}

Educational experiences appeared to contribute towards influencing participants' conception of practice. Participants who conceived practice as professional artistry, tended to have postgraduate Master's degrees (Table 3). Postgraduate education which promoted student-centeredness and critical thinking (Conneeley, 2005; Perry et al., 2011; Petty et al., 2011a) may have encouraged greater reflection and critical evaluation of practice knowledge, in particular the traditional theories and principles associated with osteopathy:

I don't see black as white, I see some studies suggest this but we could look at it this way, I try to draw on my experience and knowledge and to try and give a balanced opinion.and I'll happily question the dogma of osteopathy. (P3)

Participants who possessed formal postgraduate degrees tended to take a more critically evaluative stance towards practice. They were more comfortable with the uncertainties and ambiguities of clinical practice:

I may say to patients "I actually don't know what's going on here; it could be discogenic, you may have some degeneration. I try to be as honest and transparent as possible. (P6)

They went beyond the application and acquisition of propositional knowledge and they tended to incorporate other forms of knowledge such as personal and emotional knowledge. Their postgraduate learning may have moved their conception of practice along the continuum towards professional artistry (Fig. 1). In contrast, participants without postgraduate degrees may have been moulded from the didactic nature of undergraduate training, where the focus is on knowledge acquisition rather than critical evaluation (Wallace, 2008; Vaughan et al., 2012). These participants tended to be less questioning of their practice and uncritically accept some of the traditional osteopathic theories and principles:

As long as you keep pure to the osteopathic philosophical idea.and I suppose I still operate from a more old school point of view, where I will use palpation, and joint assessment to tell me what to do. (P1)

This may have resulted in participants adopting a more rigid and rule-governed approach to practice, applying theories more strictly to practice situations.

\subsection{View of health and disease}

Views about health and disease varied amongst study participants (Fig. 1). Half the participants expressed views which emphasised the physical and physiological aspects of the patient's problem:

.if you know that the problem in the knee is being caused by excessive rotation of the pelvis, then the ligament will be overloaded- my aim is to treat the compensations of the body. (P1)

Everyone's always got something biomechanical. they all have some mechanical factors that are contributing to their problem. (P2)

Participants who emphasised the biomedical aspects of health and disease tended to focus on 'finding and fixing' patients' problems through the application of technical skills and knowledge, suggestive of a technical rational conception of practice. These participants placed less significance on the emotional and psychological experiences of the patient. They focused on the patient's body, physical structure and biomechanics, which suggest that they viewed patients' problem through a predominantly biomedical lens. 


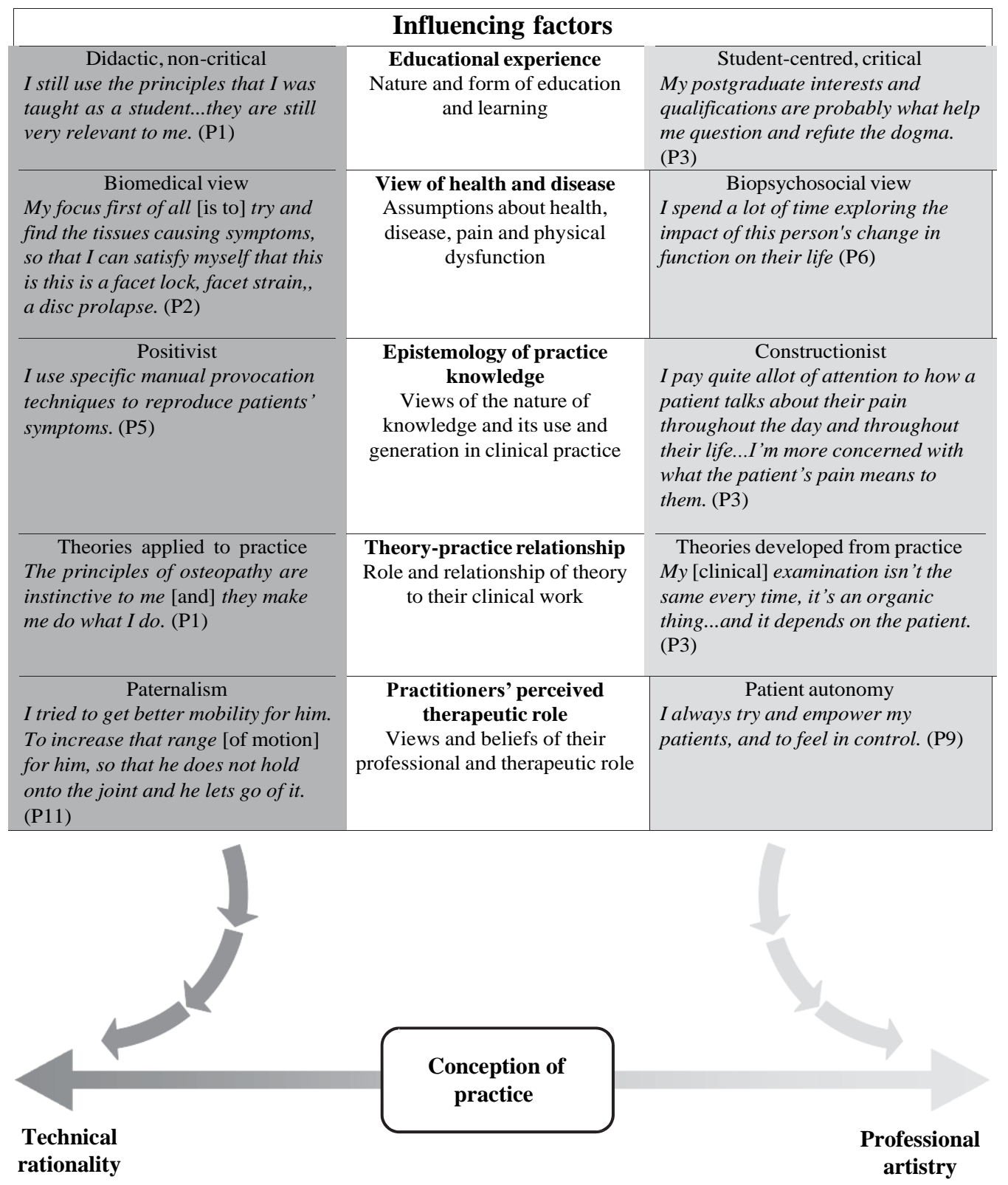

Fig. 1. Factors influencing and associated with participants' conception of clinical practice.

Whereas several other participants considered and explored patients' pain and dysfunction in the context of their family, work and social life:

I'm interested in what the pain means to the patient. I'm far less concerned with biomechanics and symmetry. I find these relatively redundant in musculoskeletal practice. (P3)

I am interested in the psychosocial aspects. I tend to try to diffuse any form of fear-related behaviours and beliefs about their problem. (P6)

These participants tended to conceive practice as professional artistry, and considered the multiple factors which impact patients' pain and disability and the complex interaction of the biological, psychological and social factors of patients' problems, suggesting a biopsychosocial view (Engel, 1980). They were driven to explore the patient's illness experience as well as the biological, biomechanical and biomedical aspects of the pain and dysfunction.

\subsection{Epistemology of practice knowledge}

How participants viewed and generated knowledge during their clinical work was associated with their conception of practice. Some participants emphasised the scientific 'facts' of clinical practice, which could be obtained through direct observation and examination procedures, akin to a positivist epistemology of knowledge (Richardson et al., 2004). However, in addition to propositional knowledge developed from physical examination, other participants incorporated information from patients' narratives which they constructed during social interaction, and is akin to a constructionist view of practice knowledge (Kinsella, 2006).

Participants that conceived practice as technical rationality, strived for accuracy and specificity in their technical skills to assess and treat a tangible dysfunction within a patient's body:

If you don't have the basics like anatomy and physiology you are never going to get the right decision. If you know your basics you can get to the right decision. (P12) 
Propositional knowledge such as anatomy and biomechanics was central to their knowledge base and technical expertise, and they sought to obtain objective facts of the patient through skillful hands-on techniques:

My primary aim is to treat, rather than 'let's sit down and discuss your problem and see what we can do about it'. (P1)

A positivist (Richardson et al., 2004) view of practice knowledge was associated with a conception of practice akin to technical rationality.

However, other participants embraced the patient's knowledge, experiences and perceptions of their own dysfunctions and realities:

Everyone is different and has different bodies, injuries, lifestyles and so many factors are different. People have different personalities, psychologies, previous histories, emotional tendencies, likes and dislikes. (P10)

These participants held views of practice knowledge which were akin to constructionism (Kinsella, 2006) and tended to conceive practice as professional artistry. They recognised the importance of listening and using language in order to construct an understanding of how patients' made sense of their problem and their lived-experience of their pain and dysfunction:

I find that talking opens up a deeper level of understanding for them and for me. (P3)

In addition to propositional knowledge developed from physical examination, they incorporated information from patients' narratives which they constructed during social interaction.

\subsection{Theoryepractice relationship}

The role theory played in clinical practice varied between participants (Fig. 1). Some participants appeared to view theory as separate from practice. For these participants biomechanical and osteopathic theories formed the basis of their practice. These theories were applied inflexibly to inform clinical actions such as examination and treatment procedures:

.my practice is based on genuine biomechanical stuff.(P5)

In contrast, some participants appeared to develop their theories from practice. Though learning from, and reflecting on practice, they developed their own theories of practice (Argyris and Schön, 1974). They tended to have personalised ideas and theories of their own which they had developed from practice:

I'm getting away from "I've got to get my hands on and get them better" to "right, this is the situation and this is how we can approach it; it's your decision, what would you like to do?" [My approach] has become much more collaborative. (P6)

Their ability to flexibly modify their theories from practice suggested that they conceived practice as professional artistry.

\subsection{Practitioners' perceived therapeutic role}

Practitioners' perceived therapeutic roles appeared to range from paternalism to patient-autonomy (Fig. 1). Some participants assumed a dominant position in the relationship with their patients:

The patient's role is to try and relax as much as possible.and follow instructions. (P8)

This is suggestive of a one-sided and paternalistic therapeutic role with their patients:
I don't want to spend time using words and wasting valuable time, when I can get on with the job and try to achieve my goal. (P1)

Participants who adopted a paternalistic role seemed to base treatment and management decisions on the type of physical dysfunction they perceived to be present. A paternalistic role resulted in participants assuming responsibility for the decisionmaking (Emanuel and Emanuel, 1992), whereby prob- lems were solved by their application of propositional knowl- edge and technical manual therapy skills. They tended not to encourage active patient involvement and clinical decisions were made on the basis of their acquisition of knowledge through skilled interaction with patients' bodies. This perceived role was associated with a technical rational conception of practice (Fig. 1).

In contrast, other participants explored patients' values, beliefs and preferences:

By giving patients choice it treats them as an adult and gives them the autonomy. (P6)

I like to spend time just talking to the person about what's going on and how it's impacting them. (P7)

They perceived that their therapeutic role was to facilitate patient autonomy and share clinical decisions (Charles et al., 1999), and this was associated with a professional artistic conception of practice.

\section{Discussion}

In this study, experienced osteopaths' conceptions of practice lay on a continuum from technical rationality to professional artistry (Fish and Coles, 1998). Participants that conceived practice as technical rationality possessed a lens which offered a relatively straightforward, mechanical view of clinical practice and their patients. A clinical 'gaze' which is fixed upon the patient's physical problem fails to consider the patient as a whole or their lived context (Marcum, 2004). These participants adopted examination approaches which emphasised obtaining factual knowledge, with a particular focus on the characteristics of the patient's body and tissues and how these related to the patients' pain, dysfunction and associated symptoms. Viewing practice as uncomplicated, and knowledge as certain and permanent, is akin to Schön's view of the 'hard high ground' of technical rational practice (Schön, 1987). Conceiving practice as technical rationality involved practitioners applying propositional scientific knowledge (biomechanical, anatomical and osteopathic theories etc) to achieve a desired goal, such as an improvement in joint and tissue mobility. This finding is consistent with findings from research investigating the clinical reasoning of musculoskeletal physiotherapists (Noll et al., 2001; Thornquist, 2006; Cruz et al., 2012). Practice akin to technical rationality has been considered an attribute of novice healthcare practitioners (Jensen et al., 1990, 1992; Unsworth, 2001; Smith et al., 2008, Smith et al., 2010), where practice is characterised as being practitioner-centred, emphasising the application of specific factual knowledge and technical skills in a routine predictable manner. In this current study, no relationship between participants' years of clinical experience and their conception of practice was found. This finding is consistent with existing research (Resnik and Hart, 2003; Resnik and Jensen, 2003; Petty et al., 2011a), and theories of expertise (Schön, 1987; Eraut, 1994), thereby supporting the notion that the development of clinical expertise and artistry, is not related to years of experience (Richardson, 1999). 
Other participants held conceptions of practice akin to professional artistry (Schön, 1987; Fish and Coles, 1998). They acknowledged the complexities and ambiguities of practice and embraced seeing practice from different viewpoints, especially patients' illness perspectives (Marcum, 2004). These participants could respond to the individuality of patients' preferences, expectations and illness experiences so that clinical actions (such as their examination and treatment procedures) as well as decisions, addressed the complexity of the situation and the individual patient. For these participants, action fitted the particulars of the patient and their situation, exhibiting a characteristic of practice which may be considered a form of 'practice wisdom' (Eraut, 1994). This finding is consistent with research conducted in musculoskeletal physiotherapy (Jensen et al., 2000; Edwards et al., 2004), and occupational therapy (Fleming, 1991a, b; Paterson et al., 2005, 2006). In this study, participants that conceived practice as professional artistry were able to bring together knowledge from different sources in an individual and patient-specific way so that they could navigate and make sense of the 'swampy lowlands' of practice (Schön, 1987). They were comfortable with viewing practice as complex, and did not resort to the strict application of rules, theories and technical skills to negotiate practice situations. They had developed individual approaches to practice; blending together their own personal attributes with their practice skills creatively and imaginatively (Higgs and Titchen, 2001b).

This study identified a number of factors which influenced or were associated with participants' conception of practice. These factors are consistent with the literature and include educational experience (Petty et al., 2011a, b), view of health and disease (Marcum, 2004), and epistemology of practice knowledge (Schön, 1987; Fish and Coles, 1998; Richardson et al., 2004; Petty et al., 2011a, b) and are discussed below.

A lack of postgraduate education was found to be associated with technical rationality. This implies that currently undergraduate osteopathic education may promote technical rationality. Recent research investigating assessment methods used in undergraduate osteopathic education suggest a focus on technical skills and knowledge, implying that technical rationality predominates (Vaughan et al., 2012). Furthermore, osteopathic education in relation to hands-on skills has remained largely unchanged for several decades (Browning, 2010). Commonly, the lecturer demonstrates a clinical technique and then instructs students to copy and practise the technique or procedure on a peer (Wallace, 2008). Such approaches to teaching and assessment may be viewed as both paternalistic and technical rational and may nurture an ongoing culture focused on technical knowledge and hands-on skill. An undergraduate curriculum which is excessively skillbased may not promote critical evaluation or prepare students for the life-long learning necessary for professional practice.

The findings from this study suggest that participants who conceived practice as technical rationality held biomedical views of health and disease and emphasised the physical and biomechanical aspects of the patient's pain and dysfunction. This view reduces patients down to a collection of clinical signs and symptoms, embodying a specific disease classification or diagnosis (Engel, 1977). This finding appears to conflict with the assertion that throughout the world osteopathy is a biopsychosocially oriented and patient-centred approach to healthcare (OCNZ, 2010; WHO, 2010; OBA, 2011).

Participants that conceived practice as technical rationality emphasised knowledge as 'facts' of the clinical situation and the patient's problem. These participants considered that they could make discoveries and obtain clinically relevant knowledge through what Schön would describe as "the application of theory and technique derived from systematic scientific knowledge" (Schön,
1987, pp. 3e4). This finding is consistent with an epistemology of practice knowledge aligned to positivism (Kinsella, 2007).

This study found that professional artistry was associated with postgraduate education in the form of Master's degree. This supports a growing body of research into how postgraduate education may help develop the practice of a range of healthcare professionals, including physiotherapists (Green et al., 2008; Rushton and Lindsay, 2010; Perry et al., 2011; Petty et al., 2011a, b), occupational therapists (Alsop and Lloyd, 2002; Conneeley, 2005), and nurses (Spencer, 2006; Drennan, 2008).

Participants who conceived practice as professional artistry held views of knowledge which were aligned with constructionism. The association between professional artistry and constructionism is consistent with the literature (Higgs et al., 2004; Kinsella, 2006), and for some participants in this study, meant that they recognised that there were multiple ways in which to see the clinical situation, and acknowledged the multiplicity of patients realities, needs and preferences (Richardson et al., 2004).

\section{Conclusion}

This study provides the first research-based knowledge of osteopaths' conceptions of clinical practice, which lay on a continuum ranging from technical rationality to professional artistry. A number of influencing factors were identified which contributed to practitioners' conception of practice and help explain their therapeutic approach and clinical decision-making. The findings from this study may assist practitioners and educators to further understand how technical rationality and professional artistry may be developed in osteopathic practitioners.

\section{Acknowledgements}

Thanks to the British College of Osteopathic Medicine, the British Naturopathic and Osteopathic Association and the Osteopathic Educational Foundation for their support of this doctoral research.

\section{References}

Alsop A, Lloyd C. The purpose and practicalities of postgraduate education. The British Journal of Occupational Therapy 2002;65:245e51.

Argyris C, Schön DA. Theory in practice: increasing professional effectiveness. Jossey-Bass; 1974.

Aristotle. The Nicomachean ethics. Boston, MA: D. Reidel; 1975.

Browning S. Teaching osteopathic students technique; using research to identify good teaching practice. International Journal of Osteopathic Medicine 2010;13: $70 \mathrm{e} 3$.

Charles K, Gafni A, Whelan T. Decision-making in the physician-patient encounter: revisiting the shared treatment decision-making model. Social Science \& Medicine 1999;49:651e61.

Charmaz K. Constructing grounded theory. London; Thousand Oaks, Calif.: Sage Publications; 2006

Conneeley AL. Study at master's level: a qualitative study exploring the experience of students. The British Journal of Occupational Therapy 2005;68:104e9.

Cruz EB, Moore A, Cross V. Clinical reasoning and patient-centred care in musculoskeletal physiotherapy in Portugal e a qualitative study. Manual Therapy 2012;17:246e50.

Drennan J. Professional and academic destination of masters in nursing graduates: a national survey. Nurse Education Today 2008;28:751e9.

Edwards I, Jones M, Carr J, Braunack-Mayer A, Jensen GM. Clinical reasoning strategies in physical therapy. Physical Therapy 2004;84:312e30.

Edwards I, Jones M, Hillier S. The interpretation of experience and its relationship to body movement: a clinical reasoning perspective. Manual Therapy 2006;11: $2 e 10$

Emanuel EJ, Emanuel LL. Four models of the physician-patient relationship. Journal of the American Medical Association 1992;267:2221e6.

Engel GL. The need for a new medical model: a challenge for biomedicine. Science 1977;196:129.

Engel GL. The clinical application of the biopsychosocial model. The American Journal of Psychiatry 1980;137:535e44. 
Eraut M. Developing professional knowledge and competence. London: Falmer; 1994.

Evans D. Changing the practice of osteopaths, chiropractors and musculoskeletal physiotherapists, in relation to the management of low back pain. Keele University; 2007 [Unpublished PhD Thesis].

Fish D. Appreciating practice in the caring professions: refocusing professional development and practitioner research. Oxford: Butterworth-Heinemann; 1998.

Fish D, Coles C. Developing professional judgement in health care: learning through the critical appreciation of practice. Oxford; Boston: Butterworth-Heinemann 1998.

Fleming MH. Clinical reasoning in medicine compared with clinical reasoning in occupational therapy. American Journal of Occupational Therapy 1991a;45: 988e96.

Fleming MH. The therapist with the three-track mind. American Journal of Occupational Therapy 1991b;45:1007e14.

Foster NE, Hartvigsen J, Croft PR. Taking responsibility for the early assessment and treatment of patients with musculoskeletal pain: a review and critical analysis. Arthritis Research \& Therapy 2012;14:205.

GOsC. General Osteopathic Council. Osteopathy in practice. London: General Osteopathic Council; 2012.

Green A, Perry J, Harrison K. The influence of a postgraduate clinical master's qualification in manual therapy on the careers of physiotherapists in the United Kingdom. Manual Therapy 2008;13:139e47.

Haw K, Hadfield M. Video in social science research: functions and forms. Routledge; 2011.

Higgs J, Fish D, Rothwell R. Practice knowledge e critical application. In: Higgs I Richardson B, Dahlgren MA, editors. Developing practice knowledge for health professionals. Edinburgh: Butterworth Heinemann; 2004. p. 89e105.

Higgs J, Titchen A. Practice knowledge and expertise in the health professions. Oxford: Butterworth-Heinemann; 2001a.

Higgs J, Titchen A. Rethinking the practice-knowledge interface in an uncertain world: a model for practice development. The British Journal of Occupational Therapy 2001b;64:526e33.

Jensen GM, Gwyer J, Shepard KF. Expert practice in physical therapy. Physical Therapy 2000;80:28e43 discussion 4e52.

Jensen GM, Shepard KF, Gwyer J, Hack LM. Attribute dimensions that distinguish master and novice physical therapy clinicians in orthopedic settings. Physical Therapy 1992;72:711e22.

Jensen GM, Shepard KF, Hack LM. The novice versus the experienced clinician: in sights into the work of the physical therapist. Physical Therapy 1990;70:314e23.

Kinsella EA. Constructivist underpinnings in Donald Schön's theory of reflective practice: echoes of Nelson Goodman. Reflective Practice 2006;7:277e86.

Kinsella EA. Technical rationality in Schön's reflective practice: dichotomous or non-dualistic epistemological position. Nursing Philosophy 2007;8:102e13.

Lindquist I, Engardt M, Richardson B. Learning to be a physiotherapist: a metasynthesis of qualitative studies. Physiotherapy Research International 2010;15: $103 e 10$

Marcum JA. Biomechanical and phenomenological models of the body, the meaning of illness and quality of care. Medicine, Health Care and Philosophy 2004;7:311e20.

NHS. National Health Service. Any qualified provider (AQP). National Health Service; 2012.

NICE. National Institute for Health and Clinical Excellence. Low back pain: early management of persistent non-specific low back pain (Clinical guideline 88) National Institute for Health and Clinical Excellence; 2009.

Nicholls DA, Gibson BE. The body and physiotherapy. Physiotherapy Theory and Practice 2010;26:497e509.

Noll E, Key A, Jensen G. Clinical reasoning of an experienced physiotherapist: insight into clinician decision-making regarding low back pain. Physiotherapy Research International 2001;6:40e51.

OCNZ. Osteopathic Council of New Zealand. Capabilities for osteopathic practice. The Osteopathic Council of New Zealand; 2010.

OBA. Osteopathy Board of Australia. Osteopathy code of conduct. Osteopathy Board of Australia; 2011.
Paterson M, Higgs J, Wilcox S. The artistry of judgement: a model for occupational therapy practice. The British Journal of Occupational Therapy 2005;68: $409 \mathrm{e} 17$.

Paterson M, Higgs J, Wilcox S. Developing expertise in judgement artistry in occupational therapy practice. The British Journal of Occupational Therapy 2006;69:115e23.

Perry J, Green A, Harrison K. The impact of masters education in manual and manipulative therapy and the 'knowledge acquisition model'. Manual Therapy 2011;16:285e90.

Petty NJ. Towards clinical expertise: learning transitions of neuromusculoskeletal physiotherapists. University of Brighton; 2009 [Unpublished Doctoral Thesis].

Petty NJ, Scholes J, Ellis L. The impact of a musculoskeletal masters course: developing clinical expertise. Manual Therapy 2011a;16:590e5.

Petty NJ, Scholes J, Ellis L. Master's level study: learning transitions towards clinical expertise in physiotherapy. Physiotherapy 2011b;97:218e25.

Polanyi M. The tacit dimension. London: Routledge \& Kegan Paul; 1967.

Resnik L, Hart DL. Using clinical outcomes to identify expert physical therapists. Physical Therapy 2003;83:990e1002.

Resnik L, Jensen GM. Using clinical outcomes to explore the theory of expert practice in physical therapy. Physical Therapy 2003;83:1090e106.

Richardson B. Professional development 2. Professional knowledge and situated learning in the workplace. Physiotherapy 1999;85:467e74.

Richardson B, Higgs J, Dahlgren MA. Recognisng practice epistemology in the health professions. In: Higgs J, Richardson B, Dahlgren MA, editors. Developing practice knowledge for health professionals. Edinburgh: Butterworth Heinemann; 2004. p. $1 \mathrm{e} 14$.

Rowan J, Jacobs M. The therapist's use of self. Buckingham: Open University Press; 2002.

Rushton A, Lindsay G. Defining the construct of masters level clinical practice in manipulative physiotherapy. Manual Therapy 2010;15:93e9.

Ryle G. The concept of mind. Harmondsworth: Penguin Books; 1949.

Schön DA. The reflective practitioner: how professionals think in action. Nueva York, EUA: Basic Books; 1983.

Schön DA. Educating the reflective practitioner. 1st ed. San Francisco, CA: JosseyBass; 1987.

Smith M, Higgs J, Ellis E. Characteristics and processes of physiotherapy clinical decision making: a study of acute care cardiorespiratory physiotherapy. Physiotherapy Research International 2008;13:209e22.

Smith M, Joy H, Ellis E. Effect of experience on clinical decision making by cardiorespiratory physiotherapists in acute care settings. Physiotherapy Theory and Practice 2010;26:89e99.

Spencer RL. Nurses', midwives' and health visitors' perceptions of the impact of higher education on professional practice. Nurse Education Today 2006;26: $45 e 53$.

Thomson OP. Clinical decision making and therapeutic approaches of experienced osteopaths. University of Brighton; 2013 [Unpublished PhD Thesis].

Thomson OP, Petty NJ, Moore AP. Clinical decision making and therapeutic approaches in osteopathy $\mathrm{e}$ a qualitative grounded theory study. Manual Therapy 2013. http://dx.doi.org/10.1016/j.math.2013.07.008.

Thornquist E. Body communication is a continuous process: the first encounter between patient and physiotherapist. Scandinavian Journal of Primary Health Care 1991;9:191e6.

Thornquist E. Face-to-face and hands-on: assumptions and assessments in the physiotherapy clinic. Medical Anthropology 2006;25:65e97.

Unsworth CA. The clinical reasoning of novice and expert occupational therapists. Scandinavian Journal of Occupational Therapy 2001;8:163e73.

Vaughan B, Sullivan V, Gosling C, McLaughlin P, Fryer G, Wolff M, et al. Methods of assessment used by osteopathic educational institutions. International Journal of Osteopathic Medicine 2012;15:134e51.

Wallace SS. Criticality, research, scholarship and teaching: osteopaths as educators e what makes a good teacher? International Journal of Osteopathic Medicine 2008;11:52e5.

WHO. World Health Organisation. Benchmarks for training in osteopathy. Geneva: World Health Organization; 2010. 